\title{
FRACTURES COMPLICATING ELEGTRO-CONVULSIVE THERAPY AND CHRONIC EPILEPSY
}

\author{
J. P. Kelly, Lancaster, England \\ From the Lancaster Moor Hospital
}

The use of electro-convulsive therapy has established itself in psychiatric practice. Opinion varies considerably about the risk of fractured limbs and spines. Accidental electric shocks have caused severe injuries to the spine and limbs, but with electro-convulsive therapy the passage of the current is briefer, the voltage is lower, the amperage is less and the size of the terminals is smaller. Nevertheless the current is sufficient to produce unconsciousness and epileptiform convulsions and in some cases contractions so great as to cause fracture of the spine or other bones. The least necessary to produce a major convulsion is about 100 volts and the duration about $0 \cdot 3$ second.

The present investigation was undertaken to assess the injuries (fractures and dislocations) complicating electro-convulsive therapy in a group of patients treated in the Lancaster Moor Hospital between 1942 and 1952. During this period of ten years 2,200 patients received electro-convulsive therapy from a single treatment to several series of treatments. In all, 37,000 convulsions were induced. Fractures of the spine, humerus, femoral neck and scapula were noted. The site distribution of the fifty-three fractures and dislocations is shown in Table I.

TABLE I

Distribution of Site of InJURy

\begin{tabular}{|cccc|cc|}
\hline Spine & $\begin{array}{c}\text { Neck of } \\
\text { femur }\end{array}$ & $\begin{array}{c}\text { Upper } \\
\text { humerus }\end{array}$ & $\begin{array}{c}\text { Coracoid } \\
\text { process }\end{array}$ & $\begin{array}{c}\text { Dislocated } \\
\text { jaw }\end{array}$ & Total \\
\hline 21 & 15 & 15 & 1 & 1 & 53 \\
\hline
\end{tabular}

The reported incidence of such injuries among patients receiving electro-convulsive therapy varies. Fractures occurred in $1 \cdot 1$ per cent of 3,000 patients treated by Meduna and Friedman (1939), excluding vertebral fractures. Nine patients among 1,000 treated by Kolb and Vogel (1942) sustained fractures. Worthing and Kalinowsky (1942) reported sixty patients treated without a fracture. Samuel (1943) recorded twelve fractures (2.8 per cent) among 420 patients.

The method employed to produce the convulsion in this series of cases was as follows. The patient lies on a bed upon an ordinary firm mattress. A small pillow is placed under the lower thoracic spine. One nurse controls the shoulders, one the thighs and the third places a gag in the mouth and controls the jaw, so that the tongue cannot be bitten and the mouth cannot be opened excessively. (One case of dislocated jaw occurred which required manipulation under general anaesthesia later to reduce it.) The electrodes are placed on the temple and the current is switched on. The common starting dose is 130 volts for $\mathbf{0 . 3}$ second; if a heavier dosage is required for subsequent shocks the voltage is raised, but it is not increased beyond 150 volts for 1 second. Treatment is repeated on alternate days.

FRACTURES OF THE SPINE

Twenty-one cases of fractured spine occurred-about 1 per cent of the cases treated. Table II shows the distribution of fractured vertebrae. Of the twenty-one cases seventeen 
TABLE II

The Distribution of Fractured Vertebrae

\begin{tabular}{|c|c|c|c|c|c|c|c|c|c|c|c|c|c|c|}
\hline Thoracic vertebrae & 4 & $\mathbf{5}$ & 6 & 7 & 8 & 9 & 10 & 11 & 12 & & & & & \\
\hline Lumbar vertebrae & & & & & & & & & & 1 & 2 & 3 & 4 & $\mathbf{5}$ \\
\hline $\begin{array}{l}\text { Number of times } \\
\text { fractured }\end{array}$ & 5 & 4 & 5 & 5 & 2 & 2 & 2 & & & & 1 & & 1 & \\
\hline
\end{tabular}

TABLE III

Number of Vertebrae Fractured

\begin{tabular}{|c|c|c|}
\hline \multirow{2}{*}{$\begin{array}{l}\text { Number of } \\
\text { vertebrae } \\
\text { fractured }\end{array}$} & \multicolumn{2}{|c|}{ Incidence } \\
\hline & Male & Female \\
\hline One & 9 & 8 \\
\hline Two & 2 & - \\
\hline Three . & 1 & 1 \\
\hline
\end{tabular}

showed a fracture of a single vertebra, two a fracture of two adjacent vertebrae (T.4 and $\pi$ ) and two a fracture of three vertebrae (Table III).

The fractures occurred throughout the thoracic spine with the exception of one case in the lumbar region in which fractures of L.2 and L.4 were combined with a fracture of T.10. The commonest site of fracture was at T.4, 5 or 6 (Fig. 1). Fractures below the level T.7 were uncommon (Fig. 2) and there was no case of fracture in the cervical region.

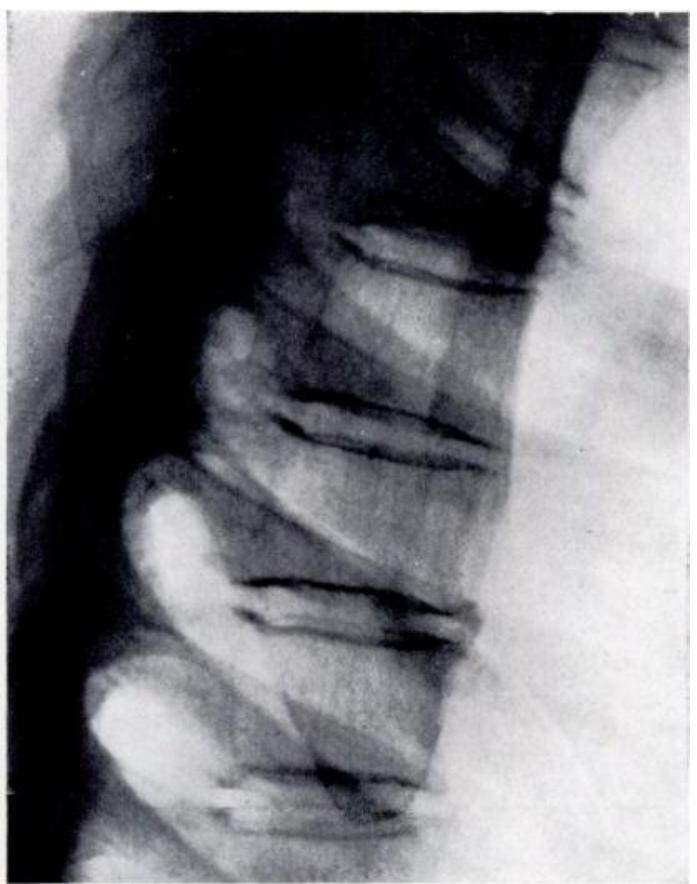

FIG. 1

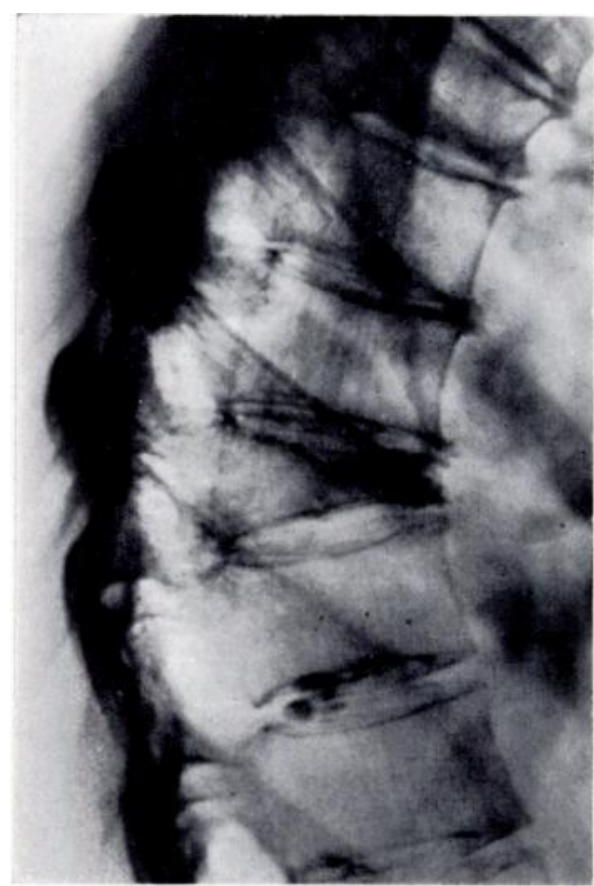

FIG. 2

Figure 1-Anterior wedge fracture of T.4 in a woman aged fifty-four, sustained during the fourth electro-convulsion. There is no comminution and the disc spaces above and below the fracture are well preserved. Figure 2-Anterior wedge fracture of T.8 in a woman of forty-five, sustained during the second electro-convulsion. There is also a depression in the centre of the superior surface of T.8 where the disc has herniated into the body. T.5 is also fractured.

VOl. 36 B, No. 1, FEBRUary 1954 
All the fractures were confined to the bodies of the vertebrae, there being no involvement of the spines, laminae or pedicles. There was no case of hyperextension fracture, fracturedislocation or cord damage. No deaths due to fractured spine occurred. The segment of the spine T.4 to T.7 is the most vulnerable and here the spine has the least flexibility and is subjected to powerful muscle action.

Most fractures (80.9 per cent) occurred during convulsions other than the first (Table IV). This might suggest that damage leading to softening is caused by the first or early convulsions.

TABLE IV

InCIDENCE of Fracture Related to Number of Treatments

\begin{tabular}{|c|c|}
\hline Convulsion & Number of cases showing fracture \\
\hline First . . & 4 \\
\hline Second . & 8 \\
\hline Third. & 2 \\
\hline Fourth & 5 \\
\hline Fifth . & 1 \\
\hline Seventh & 1 \\
\hline
\end{tabular}

TABLE $\mathrm{V}$

Record of Cases of Fractured Stine

\begin{tabular}{|c|c|c|c|}
\hline Sex & Age & $\begin{array}{l}\text { Convulsion at which } \\
\text { fracture occurred }\end{array}$ & Site of fracture \\
\hline $\mathrm{F}$ & 54 & 4 & T.4 \\
\hline $\mathrm{F}$ & 56 & 2 & T.4 \\
\hline II & 29 & 2 & T.4 \\
\hline M & 18 & 3 & T.4 and 5 \\
\hline M & 38 & 2 & T.4 and 5 \\
\hline M & 65 & 1 & T.5 \\
\hline $\mathbf{F}$ & 49 & 4 & T.6 \\
\hline $\mathrm{F}$ & 59 & 4 & T. 6 \\
\hline $\mathrm{F}$ & 58 & 3 & T.6 \\
\hline II & 47 & 2 & T.6 \\
\hline $\mathbf{M}$ & 53 & 1 & T.6 \\
\hline $\mathrm{F}$ & 22 & i & T.7 \\
\hline M & 53 & 2 & T.7 \\
\hline$M$ & 57 & 4 & T.7 \\
\hline M & 62 & 5 & T.7 \\
\hline $\mathbf{M}$ & 28 & 2 & T.7, 9 and 10 \\
\hline $\mathrm{F}$ & 45 & 2 & T.8 \\
\hline $\mathbf{M}$ & 45 & 1 & T.8 \\
\hline $\mathrm{F}$ & 38 & 7 & T.9 \\
\hline $\mathrm{F}$ & 54 & 4 & T.10, L. 2 and 4 \\
\hline M & 73 & 2 & T.5 \\
\hline
\end{tabular}

Brailsford has termed the fracturc "the disc repercussion fracture" because it gave the impression that the disc surfaces had been hammered out by repeated blows. The fracture usually shows as a depression of the superior surface of the vertebral body and in the antero-posterior view this shows as a horizontal line of increased density (Figs. 3 and 4). The lateral view is the more valuable. It is not always easy to get a good lateral film of the upper thoracic spine and the overlapping glenoid cavity makes interpretation of any but the best quality films difficult.

Table V shows details of each of the twenty-one cases of fractured spine. 


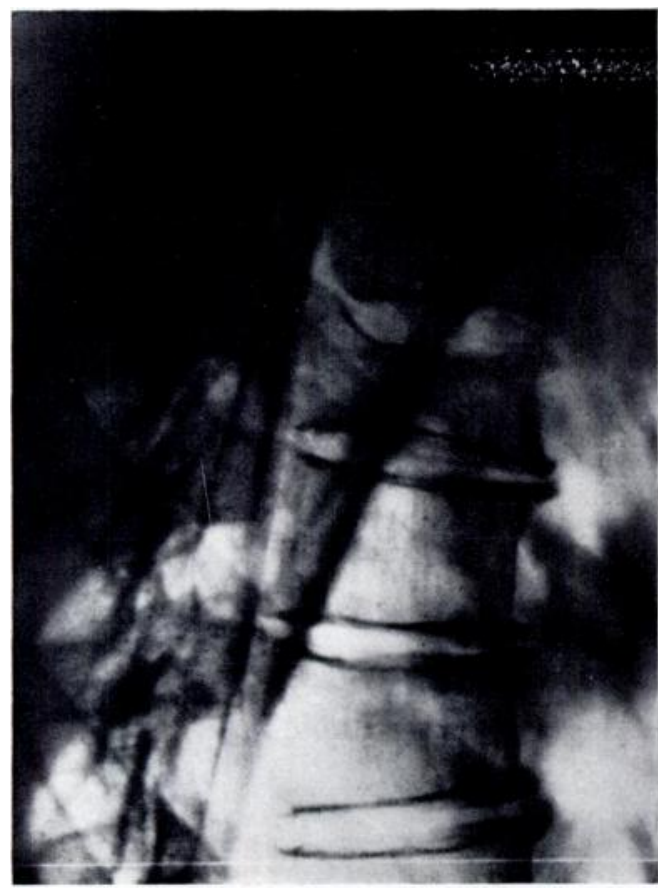

FIG. 3

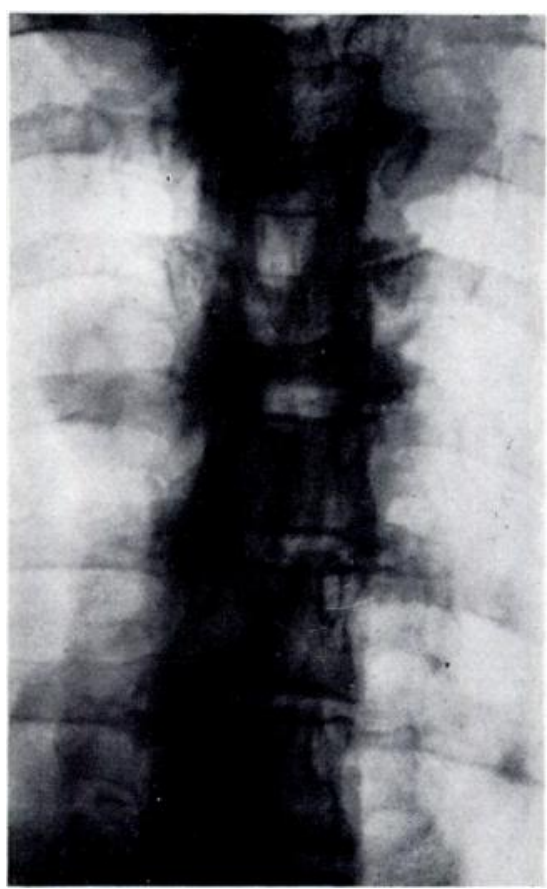

FIG. 4

Figure 3-Disc repercussion fracture. There is depression of the superior surface of T.6 with enlargement of the disc space between T.5 and 6. Figure 4-Anterior wedge fracture of T.4 showing the fractured vertebral body as a horizontal line of increased density.

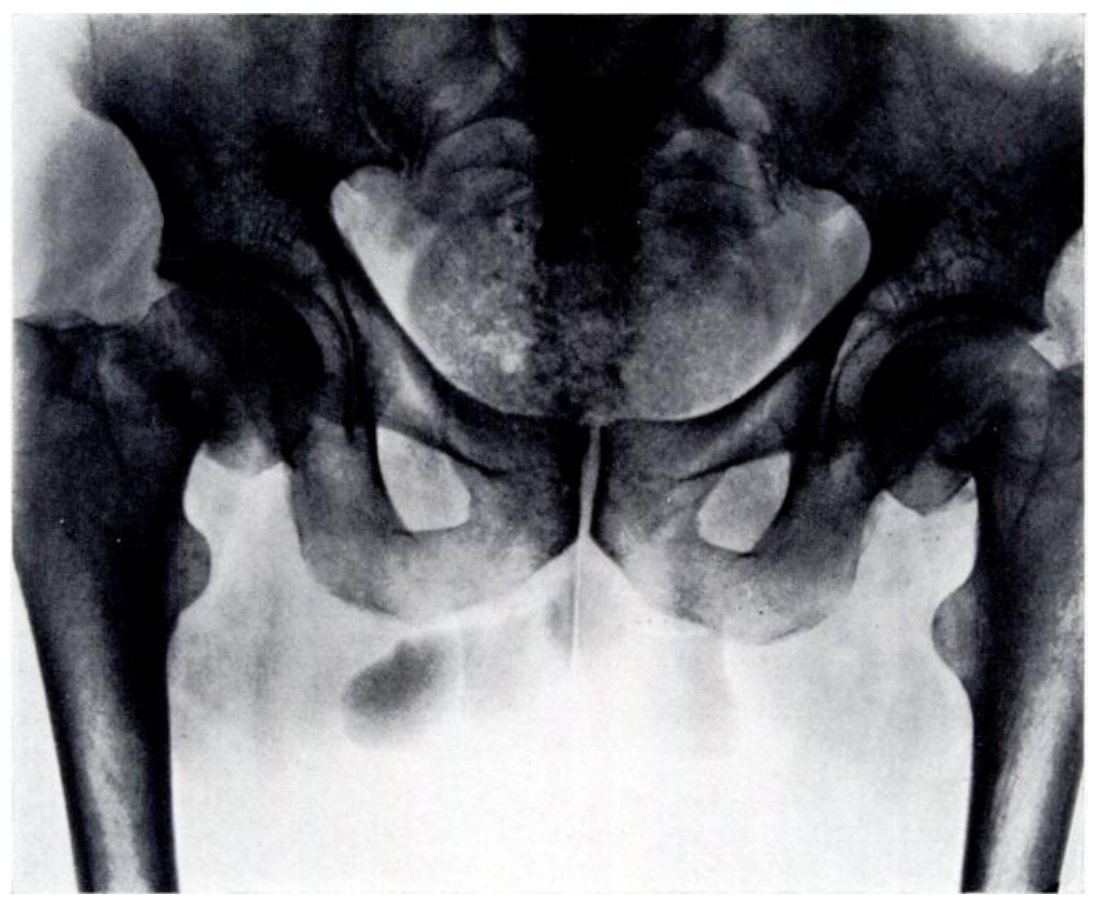

Fig. 5

Bilateral fractures of neck of femur in man of thirty-nine years during the first electro-convulsion. He died within twenty-four hours from acute pulmonary oedema. 


\section{FRACTURES OF THE FEMUR}

Fifteen cases of fractured neck of femur occurred (Table VI).

The high incidence of fracture after convulsions other than the first is again noted (Table VII).

The site of fracture was through the neck of the femur and in no case was there a coincident fracture of other bones. In one case bilateral fracture of the neck of the femur occurred during the first convulsion (Fig. 5). This was in a man of thirty-nine years. He died within twenty-four hours from acute pulmonary oedema confirmed at necropsy. There was one case of advanced Paget's disease. Treatment of these fractures was along the usual lines, either by nailing or by osteotomy.

TABLE VI

Clinical Details in Fifteen Cases of Fracture of the Neck of the Femur

\begin{tabular}{|c|c|c|c|c|c|c|}
\hline \multirow{2}{*}{$\begin{array}{l}\text { Number } \\
\text { of cases }\end{array}$} & \multirow{2}{*}{$\begin{array}{l}\text { Average } \\
\text { age }\end{array}$} & \multicolumn{2}{|c|}{ Sex } & \multicolumn{2}{|c|}{ Side } & \multirow{2}{*}{ Incidence of fracture } \\
\hline & & $\mathbf{M}$ & F & Right & Left & \\
\hline 15 & 53 years & 6 & 9 & $\begin{array}{c}11 \\
\text { (one bil }\end{array}$ & $\begin{array}{c}\mathbf{5} \\
\text { tteral) }\end{array}$ & $\begin{array}{c}0.7 \% \text { of } 2,200 \text { cases treated } \\
28 \cdot 3 \% \text { of the } 53 \text { cases of fracture }\end{array}$ \\
\hline
\end{tabular}

TABLE VII

Incidence of Fracture Related to Number of Treatments

\begin{tabular}{|l|c|}
\hline Convulsion & Number of cases with fractured neck of femur \\
\hline First . & 2 \\
\hline Second & 5 \\
\hline Third . & 4 \\
\hline Fourth $\cdot$ & 1 \\
\hline Fifth . & 1 \\
\hline Sixth . & 2 \\
\hline $86.6 \%$ of fractures occurred after convulsions other than the first \\
\hline
\end{tabular}

FRACTURES OF THE UPPER HUMERUS

It is generally agreed that fractures of the upper extremity during electro-convulsive therapy occur almost exclusively around the shoulder joint. Such fractures occurred in fifteen cases, the average age being forty-nine years, with a sex incidence of two females to one male. The type of fracture varied from a simple avulsion of the greater tuberosity to a comminuted fracture-dislocation of the upper end of the humerus. No case of dislocation of the humeral head without fracture was observed. In two cases the dislocation was posterior. Posterior dislocation of the humerus during convulsive therapy has been previously recorded by Samuel (1943). Two of the cases showed associated fracture of the scapula, one of the axillary border near the lower angle and the other of the anterior margin of the glenoid cavity. No fracture occurred in the first two convulsions (Table VIII).

\section{DISLOCATION OF THE JAW}

Dislocation of the jaw either on one or both sides is a fairly frequent occurrence and reduction is performed at a stage when the muscular contractions are becoming less. 
Occasionally this is not possible and a general anaesthetic is required later to reduce the dislocation. One such case is included in this series.

TABLE VIII

Incidence of Fracture Related to Number of Treatments

\begin{tabular}{|l|c|}
\hline Convulsion & $\begin{array}{c}\text { Number of cases of fracture or } \\
\text { fracture-dislocation of upper humerus }\end{array}$ \\
\hline First & 0 \\
\hline Second $\cdot$ & 0 \\
\hline Third $\cdot$ & 1 \\
\hline Fourth $\cdot$ & 3 \\
\hline Fifth $\cdot \cdot \cdot$ & 1 \\
\hline Sixth $\cdot \cdot$ & 5 \\
\hline Eighth $\cdot$ & 3 \\
\hline Eleventh $\cdot$ & 1 \\
\hline Nineteenth & 1 \\
\hline
\end{tabular}

\section{DISGUSSION}

Fatal complications of electro-convulsive therapy are rare and in this series of 2,000 cases there was only one death. The severity of the injury in the fractured spines was not great, fixation was not necessary and no neurological lesions occurred. Six patients who had sustained fractured spines not less than two years before were examined. They had no complaint of pain or tenderness. There was a slight kyphosis noticeable in two patients only. The fractured vertebrae had consolidated well and the disc spaces were well preserved (Figs. 6 and 7). In contrast, fracture of the neck of the femur is a serious injury, as is also fracture-dislocation of the humerus. With these patients the accepted and desired methods of treatment cannot always be applied and it is a matter of experience to choose a method that will be satisfactory in the individual case. Sogliani (1939) reported a fracture of the greater trochanter but, apart from this, fractures of the lower limb other than of the femoral neck have not been recorded. Although fracture of the femoral neck is a rare injury during electro-convulsive therapy, when it occurs it is often bilateral (Somers and Richardson 1939).

In two cases of fracture-dislocation of the shoulder the dislocation was posterior. This injury was possibly due to the upper humeral shafts being held while the spine and scapulae came forwards in the initial flexion phase of the convulsion. Any restraint considered necessary to the upper limbs should be applied to the front of the glenoids rather than to the humeral shafts. Meggendorfer (1940) actually recommended pulling the upper arm forwards during the convulsion. Other fractures in the upper limb, except fractured scapula, are very uncommon.

It is generally agreed that the incidence of fracture has been reduced since electroconvulsive therapy replaced cardiazol. According to Smith et al. (1942) the incidence of fractures has been reduced from 22 per cent to 5 per cent. Nevertheless fractures do occur in spite of precautions and technical advances, and in many cases no predisposing factor can be found. It is interesting that the greatest incidence of fracture of the spine occurs in the upper thoracic and mid-thoracic regions whether the convulsions are induced electrically, by cardiazol, or by tetanus. The wedging of the vertebra suggests that it might be brought about by the sudden flexion spasm which occurs sometimes at the beginning of the fit. The

VOL. 36 B, No. 1, FEBRUARY 1954 
fact that posterior dislocation of the humerus occurred on two occasions also favours the view that the injury occurred at the flexion stage of the convulsion. The second type of fractured vertebra seen was the " disc repercussion" fracture in which the disc is forced into the vertebral body by fracture of its superior surface. It is suggested that this is due to severe longitudinal compression of the spine, and the most likely time for this to occur is when the patient is in opisthotonos. Hence a neutral position of the spine, neither flexed nor hyperextended, during the fit is desirable to diminish the risk of fracture, and the intensity of the convulsion should be lessened either by the administration of a relaxant such as a curare preparation or "by inducing slowly developing seizures by means of the lowest possible current intensity" (Kalinowsky and Hock 1952).

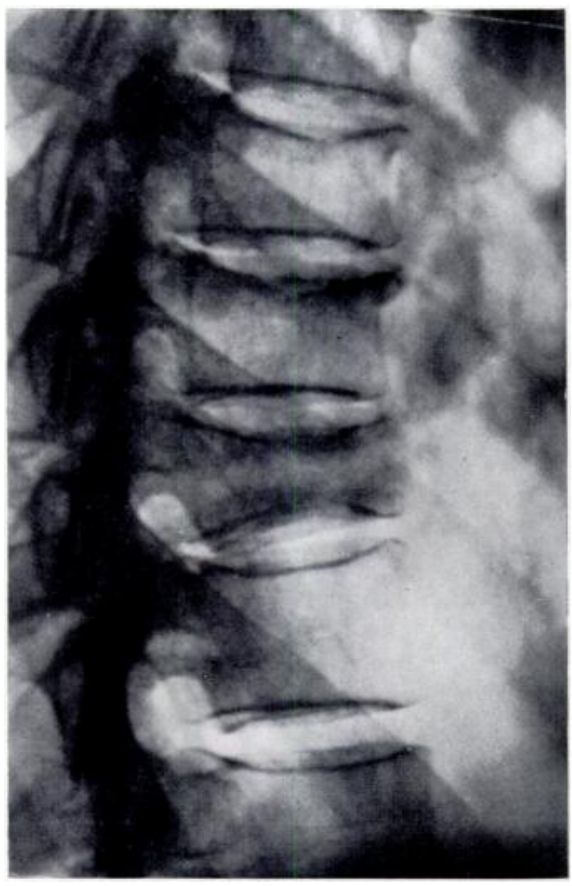

FIG. 6

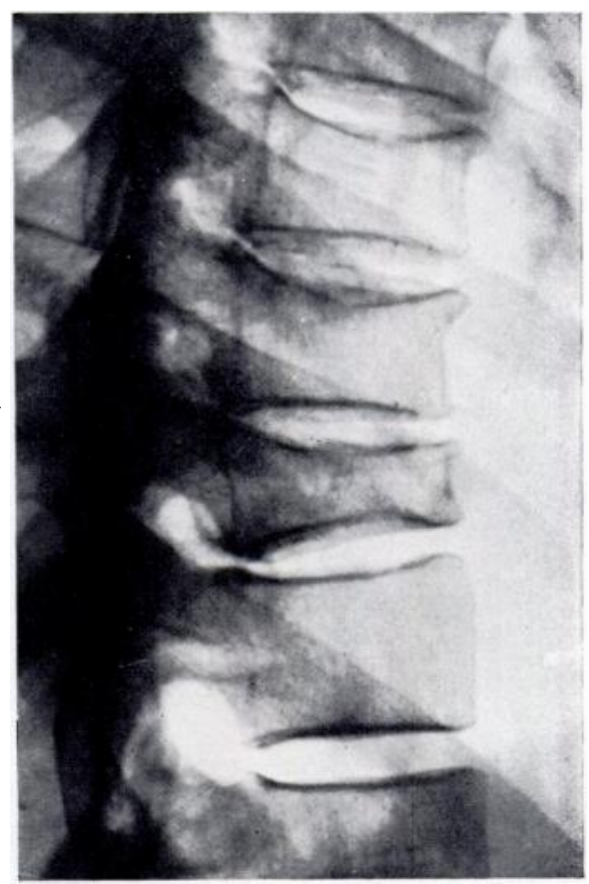

FIG. 7

Wedge fracture T.8 and 9 in woman of thirty-eight complicating the seventh electroconvulsion (Fig. 6). The patient was treated without immobilisation and seven years later was re-examined and found free from symptoms. The fracture has consolidated and the disc spaces above and below are well preserved (Fig. 7).

\section{FRACTURES IN CASES OF PSYGHOSIS WITH GHRONIC EPILEPSY}

Having noted that the incidence of fracture during electro-convulsive therapy was $\mathbf{2} \cdot \mathbf{4}$ per cent, of which fractured spine accounted for 1 per cent, the writer decided to examine cases of psychosis with chronic epilepsy and to determine the incidence of fracture, if any, in these cases and compare it with that complicating electro-convulsive therapy. Fifty-two patients were examined, of whom twenty-four were women and twenty-eight men; the thoraco-lumbar spine was radiographed in all. Fractures were not known to have occurred in any of these cases. No fracture of the long bones was found. Four cases of fracture of the spine were discovered, an incidence of 7.7 per cent. The incidence of fractured spine as reported in epileptics varies considerably. Cook and Sands (1941) found it to be $10 \cdot 4$ per cent. Caplan (1946) found nine fractures (33 per cent) in twenty-seven epileptic patients, mostly in the lower thoracic spine. Reed and Dancey (1940) reported an incidence of $34 \cdot 2$ per cent. Worthing and Kalinowsky (1942) found two fractures in forty-two epileptics. Others report 
an incidence of up to 66 per cent (Moore, Winkelman and Solis-Cohen 1941). The four cases in this series concerned men with an average age of sixty-one years. The average age of male epileptics examined was $\mathbf{4 5 \cdot 7}$ years. The average age of female epileptics examined was forty-nine years. Age does not appear to be an important factor in the causation of fractured spine in these cases. The fact that all the fractures occurred in men is probably due to their more powerful musculature.

TABLE IX

Site of Spinal Fracture in Four Epileptic Patients

\begin{tabular}{|c|c|c|}
\hline Sex & Age & Site of fracture \\
\hline M & 66 & T.7 L.3 \\
M & 47 & T.8 \\
M & 54 & T.12 \\
M & 77 & L.3 and 4 \\
\hline
\end{tabular}

The site of the fracture differed from that of fractures complicating electro-convulsive therapy (Table IX). No fracture of the thoracic spine above T.7 was found. There was one case of fracture in the lumbar spine alone (L.3 and 4). In half of the cases one vertebra was involved-namely T.8 and T.12; in the other half two vertebrae were affected (Fig. 8). Because of the patients' mental state it was not possible to get a reliable history of the onset of backache

TABLE $X$

Comparison of Fractures Caused by Electro-convulsive Therapy with Those Caused by Chronic Epilepsy

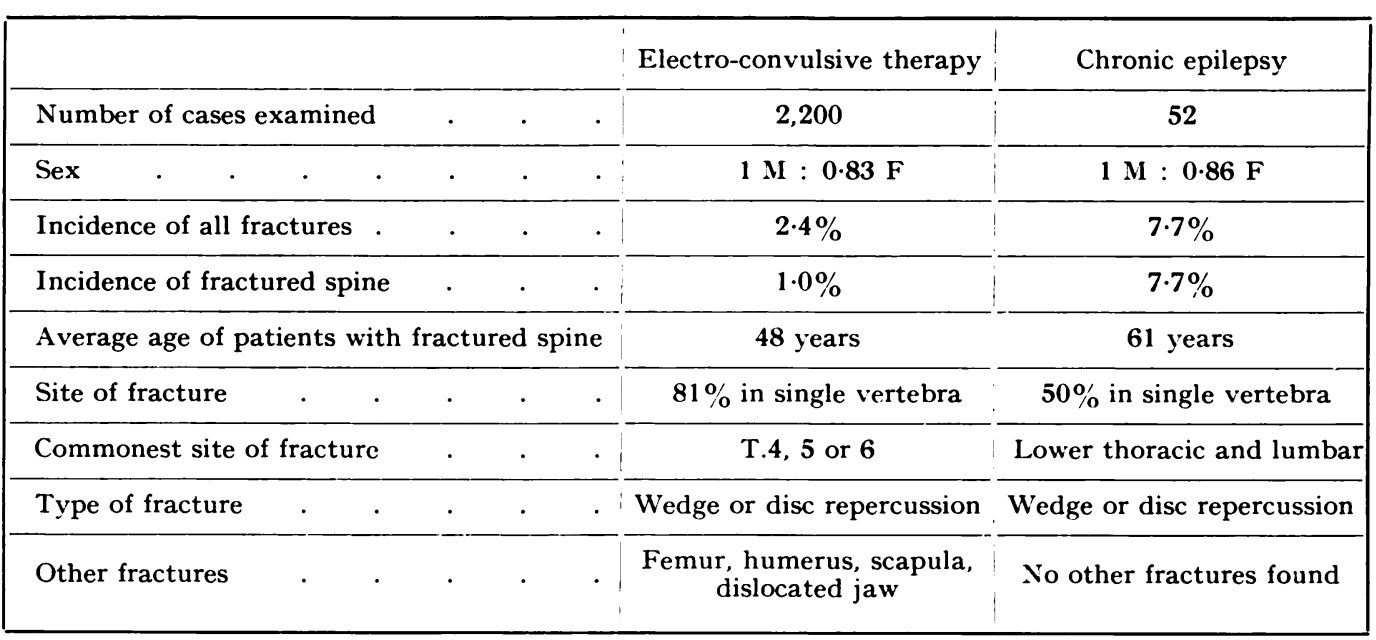

after a fit, but all the fractures appeared of long standing. The type of fracture was similar to that complicating electro-convulsive therapy, the body of the vertebra alone being involved; in one case the radiographs showed a marked concavity of the upper surface of the body of L.3 with the disc spaces on both sides well preserved. This was an old " disc repercussion" fracture, similar to that found after electro-convulsive therapy (Fig. 9).

It has been stated that these fractures are quite different from those seen after convulsive therapy (Worthing and Kalinowsky 1942) (Table X). It is suggested that they might be due to 
the actual fall. However, it can be seen from this group of cases that, as in fractures of the spine caused by electro-convulsive therapy, the body of the vertebra alone is affected, and in one case there was a marked concavity of the upper surface of the vertebral body with herniation of the disc into the vertebral body. This was an old " disc repercussion " fracture similar to that found after electro-convulsive therapy. The difference in the site of fracture in the two groups might be explained by the fact that some epileptics are standing when the fit occurs, whereas patients having electro-convulsive therapy are lying down and the fit is controlled. When the patient is standing the knees are extended and the pelvis is fixed by the strong hamstring muscles. Forced flexion of the spine at this stage puts considerable stress on the lumbo-sacral region and lower half of the spine. Hence it is suggested that the site of fracture is different from that complicating electro-convulsive therapy because the fulcrum of movement is lowered from the upper thoracic level.

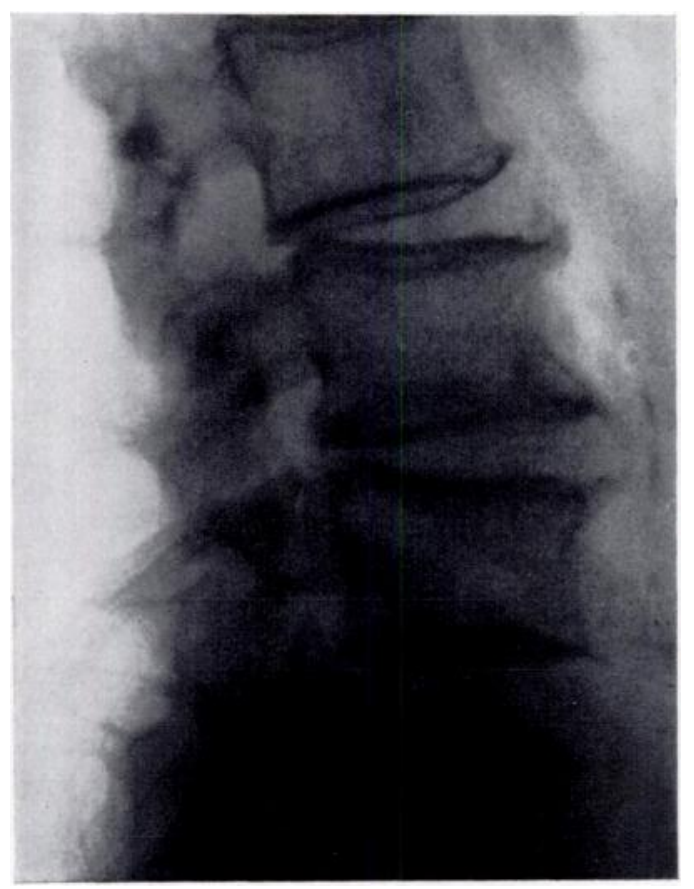

FIG. 8

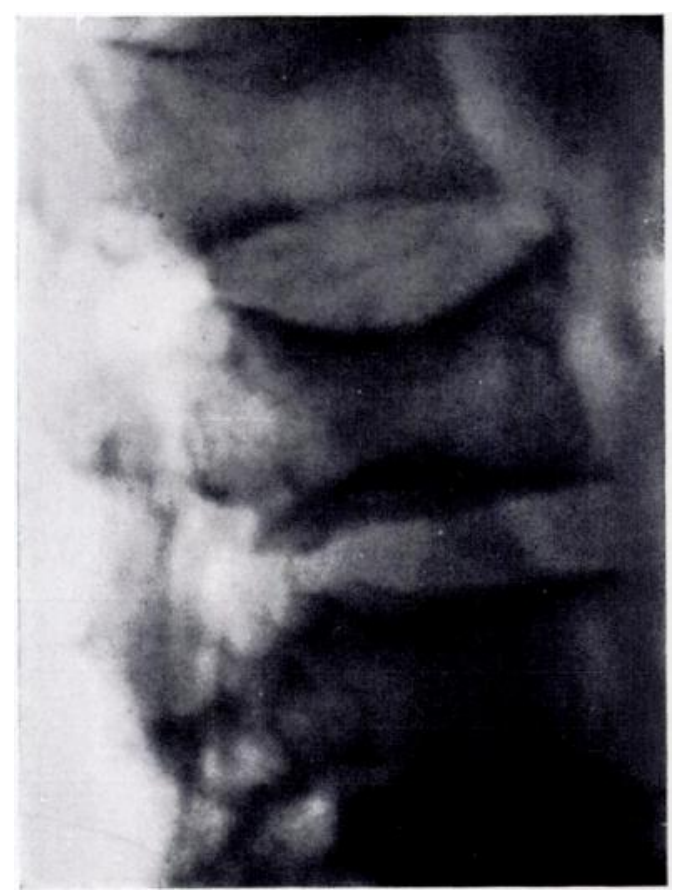

Fig. 9

Figure 8-Old wedge fracture L.3 and 4 in male chronic epileptic aged seventy-seven. This was the only case amongst the epileptics in which fracture of the lumbar spine alone occurred. Figure 9-Old disc repercussion fracture in male chronic epileptic. There is well marked concavity of the upper surface of the body of L.3 with relative enlargement of the disc space between L.2 and 3 . This patient also had an anterior wedge fracture of T.7.

\section{SUMMARY}

1. A study of 2,200 patients receiving electro-convulsive therapy showed that fifty-three sustained fractures or dislocations-an incidence of $\mathbf{2 . 4}$ per cent. Of the fifty-three injuries, twenty-one occurred in the spine, fifteen in the neck of femur, fifteen in the upper end of humerus, one in the coracoid process; one dislocated jaw required anaesthesia for its reduction (other cases of transient dislocation of the jaw are excluded).

2. The incidence, site, and type of spinal fractures are recorded, and the relation of the fracture to the first convulsion is noted. No late changes were found in the spines of patients examined two years or more after treatment. A neutral position of the spine during the convulsion is believed to diminish the risk of fracture. 
3. Fracture of the neck of the femur is a serious injury in these patients. In one case the injury was bilateral.

4. The fifteen cases of fracture-dislocation of the upper humerus are analysed. They included two cases of posterior dislocation of the humeral head; the possible mechanism of this is explained and a method of prevention suggested.

5. Fifty-three patients with chronic epilepsy with psychosis were examined. Four cases of fractured spine were discovered. The site of fracture was different from that of fractures caused by convulsive therapy and a reason for this is suggested. The type and mechanism of the fracture are similar in the two groups.

I am most grateful to Mr Ian D. Kitchin for his helpful advice and criticism; and to Dr J. Silverston, Medical Superintendent, Lancaster Moor Hospital, without whose help it would have been impossible to gather the necessary data.

\section{REFERENCES}

Brailsford, J. F. (1948): The Radiology of Bones and Joints. Fourth edition, 392. Lonion: J. \& A. Churchill Ltd.

C.API.AN, G. (1946): Fractures of Dorsal Vertebrae in Epilepsy and Convulsion Therapy. Journal of Mental Science, 92, 766

Cerletti, U., and Bini, L. (1938): Bollettino della R. Accademia Medica, Roma, 64, 36.

Cook, L. C., and SANDS, D. E. (1941): Spinal Injuries in Convulsion Therapy. Journal of Mental Science, 87, 230.

Kalinowsky, L. B., and Hock, P. H. (1952): Shock Treatments, Psychosurgery and Other Somatic Treatments in Psychiatry, 154. New York: Grune \& Stratton Inc.

Kolb, L., and Vogel, V. H. (1942): The Use of Shock Therapy in 305 Mental Hospitals. American Journal of Psychiatry, 99, 90.

Meduna, L. (1937): Die Konvulsionstherapie der Schizophrenie. Halle: Marhold.

Meduna, L. von, and Friedman, E. (1939): The Convulsive-Irritative Therapy of the Psychoses. Journal of the American Medical Association, 112, 501.

Meggendorfer, F. (1940): Elektrokampfbehandlung der Psychosen. Deutsche Medizinische Wochenschrift, 66, 1,155 .

MEgGendorfer, F. (1942): Zur Klinik des Elektrokrampfes. Nervenarzt, 15, 49.

Moore, M. T., Winkelman, N. W., and Solis-Cohen, L. (1941): Asymptomatic Vertebral Fractures in Epilepsy. Journal of Mental and Nervous Diseases, 94, 309.

ReEd, G. E., and Dancey, T. E. (1940): Compression Fractures of the Vertebral Bodies Following Induced and "Idiopathic" Convulsions. Canadian Medical Association Journal, N.S. 42, 38.

SAmuel, E. (1943): Some Complications Arising During Electrical Convulsive Therapy. Journal of Mental Science, 89, 81.

Sogliani, G. (1939): Elettroschockterapia e cardiazolterapia. Rassegna di studi psichiatrici, 28, 652.

Somers, D. C., and Richardson, R. P. (1939): Bilateral Fracture of the Femoral Necks Caused by Metaazol Convulsions. American Journal of Psychiatry, 95, 1,193.

Smith, L. H., Hughes, J., Hastings, D. W., and Alpers, B. J. (1942): Electroshock Treatment in the Psychoses. American Journal of Psychiatry, 98, 1,193.

Worthing, H. J., and Kalinowsky, L. B. (1942): The Question of Vertebral Fractures in Convulsive Therapy and in Epilepsy. American Journal of Psychiatry, 98, 534, 535. 